\title{
A CONTRIBUIÇÃO DAS UNIVERSIDADES ESTADUAIS (UES) PARA O ENSINO SUPERIOR NO BRASIL
}

\author{
C.M. LOPES $^{1^{*}}$ e G.O. PASSOS ${ }^{2}$ \\ ${ }^{1}$ Universidade Federal do Piauí - UFPI \\ ${ }^{2}$ Universidade de Brasília - UnB \\ cleciom.lopes-the@hotmail.com*
}

Artigo submetido em fevereiro/2015 e aceito em junho/2015

DOI: $10.15628 /$ holos.2015.2737

\section{RESUMO}

Analisa-se a participação das universidades estaduais no ensino superior do Brasil, comparando-as com as federais, municipais e privadas quanto ao número de instituições, vagas, ingressantes, matrículas e concluintes antes e depois da Lei de Diretrizes e Bases da Educação Nacional. Pergunta-se: qual a contribuição das UEs para o ensino superior brasileiro e que efeitos as inovações da LDB provocaram no setor? Deseja-se dimensionar essa participação, comparando a parcela de contribuição das UEs com a dos demais segmentos antes das inovações da lei geral. Tomam-se por base os Censos do Ensino Superior realizados pelo INEP, analisando a proporção do segmento em relação ao total. Constatou-se que as estaduais são as primeiras instituições universitárias e que, salvo nas primeiras décadas, quando a federalização subtraiu algumas unidades, até 1996, ampliava sua participação com $20 \%$ das instituições, $15 \%$ dos ingressantes, $17 \%$ das matrículas, $19 \%$ de concluintes e $13 \%$ das vagas. Desde então, apesar dos acréscimos, tem reduzido sua fatia, tendo, em 2013, $19 \%$ das universidades, $5 \%$ das vagas, $8 \%$ dos ingressantes, $13 \%$ das matrículas e $14 \%$ dos concluintes, não acompanhando o crescimento das federais e, principalmente, das privadas que, favorecidas pelas alterações na legislação, tornaram-se o maior segmento. Conclui-se, então, que a participação das universidades estaduais no ensino superior brasileiro tem experimentado ora ampliação, ora redução, mas sempre favorecendo o acesso ao ensino superior de grandes camadas da população brasileira.

PALAVRAS-CHAVE: Ensino superior. Educação brasileira. Universidades estaduais. Ensino superior estadual.

\section{THE CONTRIBUTION OF UNIVERSITIES STATE (UES) FOR HIGHER EDUCATION IN BRAZIL}

\begin{abstract}
An analysis of the participation of the state universities in higher education in Brazil, comparing them with the federal universities, municipal and private institutions in terms of the number of institutions, places, entering students, registrations and graduating students before and after the Law of Directives and Bases of National Education (LDBE). The question is: What is the contribution to the brazilian higher education and what effects the LDBE innovations caused in this sector. We wish to scale this participation, comparing the share of contribution of the state universities with the other segments of the innovations before the general law. The basis are the Census of Higher Education conducted by INEP, analyzing the proportion of relative to the total segment. It was found that the state are the first university institutions that, except in the first decades
\end{abstract}

when the federalization subtracted from some units, until 1996, it expanded its participation with $20 \%$ of institutions, $15 \%$ of entering students, $17 \%$ of registrations, $19 \%$ of graduates and $13 \%$ of places. Since then, despite the additions, it has reduced its share, and in $2013,19 \%$ of the universities, $5 \%$ of the vacancies, $8 \%$ of entering students, $13 \%$ of registrations and $14 \%$ of graduating students, not following the development of the federal universities and, especially, of the private educational institutions, more favoured to changes in legislation, became the largest in that segment. It is concluded that, the participation of the state universities in the Brazilian higher education has experienced sometimes enlargement, sometimes rollback, but always promoting access to higher education of large crosssections of the population.

KEYWORDS: Higher education. Brazilian education. Universities state. State higher education. 


\section{INTRODUÇÃO}

As universidades estaduais, como observaram Sampaio, Balbachesky e Peñaloza (1998, p. 04), "constituem um segmento específico do ensino superior brasileiro", pois, explicam os autores, se, por um lado, "estão fora do âmbito de atuação do Ministério da Educação [...], sendo mantidas e fiscalizadas por seus respectivos Estados", por outro, ampliam as possibilidades de acesso ao ensino superior gratuito. Muitas vezes, dado que, no geral, localizam-se fora das capitais, interiorizando a oferta e, por conseguinte, democratizando o ingresso para uma parcela da população tradicionalmente excluída.

Este trabalho analisa a participação dessas universidades no ensino superior do Brasil, comparando o número de instituições, vagas oferecidas, ingressantes, matrículas e concluintes do segmento com o de suas congêneres federais, municipais e privadas, em dois momentos, antes e depois da Lei de Diretrizes e Bases da Educação Nacional. Pergunta-se: qual a contribuição das instituições estaduais para o ensino superior brasileiro? Que efeitos as inovações da LDB provocaram no setor?

A intenção é dimensionar essa participação, comparando sua parcela de contribuição com a dos demais segmentos e identificando os efeitos provocados pela Lei de Diretrizes e Bases da Educação Nacional na configuração do setor. Para isso, tomam-se por base os Censos do Ensino Superior realizados pelo Instituto Nacional de Estudos e Pesquisas Educacionais (INEP), analisando a proporção de cada segmento em relação ao total das universidades brasileiras.

Os resultados são expostos em cinco partes, incluindo esta introdução que é a primeira. A segunda traça a trajetória das universidades estaduais mantidas pelos estados, desde o surgimento das primeiras instituições até 1980. A terceira configura sua participação no ensino superior entre 1980 e 1996, comparando número de instituições, vagas, matrículas e concluintes em relação aos segmentos federal, municipal e privado. A quarta, do mesmo modo que a anterior, configura a participação e faz a mesma comparação, mas no período de 1996 a 2013. Na quinta parte, concluise, dimensionando a participação das universidades estaduais frente aos demais segmentos e identificando os efeitos provocados pela Lei de Diretrizes e Bases da Educação Nacional na configuração do setor.

\section{SURGIMENTO, CRESCIMENTO E TRANSFORMAÇÕES DO SEGMENTO DAS UNIVERSIDADES ESTADUAIS NO ENSINO SUPERIOR BRASILEIRO: MARCOS E MARCAS DE UMA TRAJETÓRIA}

Segundo Sampaio, Balbachesky e Peñaloza (1998), no desenvolvimento do ensino superior brasileiro, "é possível identificar três momentos que marcam" a trajetória das universidades mantidas pelos estados da federação. Neste item, expõe-se o surgimento das primeiras instituições universitárias estaduais e, em seguida, marca-se sua retração e expansão, delineiando-se os dois primeiros momentos de que falam Sampaio, Balbachesky e Peñaloza (1998).

O primeiro momento, iniciado em 1912 e findo em meados da década de 1940, foi marcado pela criação de instituições universitárias por iniciativa de líderes políticos, intelectuais e representantes da sociedade local. Datam, desse período, as seguintes: Universidade do Paraná, 
Universidade de São Paulo, Universidade do Rio Grande do Sul, Universidade da Bahia e Universidade de Pernambuco, dentre as quais se destacam:

- Universidade do Paraná - criada em 1912, é considerada a primeira universidade brasileira, antes mesmo da institucionalização do modelo de organização do ensino através do Estatuto das Universidades Brasileiras (Decreto 19.851, de 11 de abril de 1931) (BRASIL, 1931). Foi uma iniciativa de grupos locais apoiados pelo governo estadual;

- Universidade de São Paulo (USP) - criada em 1934, consoante Cardoso (1982), em decorrência de vários fatores, dentre eles: a crise oligárquica brasileira, a necessidade de grupos locais, em especial o reunido em torno do jornal "O Estado de São Paulo", de formar "elites intelectuais" para superar a crise, a Revolução de 30 com seu ímpeto planejador e também os esforços do interventor federal no Estado de São Paulo;

- Universidade Estadual do Rio Grande do Sul - criada em 1934 pelo Decreto Estadual 5.758, de 28 de novembro de 1934, assinado pelo Interventor Federal no Estado do Rio Grande do Sul, tinha como fito "dar uma organização uniforme e racional ao ensino superior no Estado, elevar o nível da cultura geral, estimular a investigação científica e concorrer eficientemente para aperfeiçoar a educação do indivíduo e da sociedade" (UFRGS, 2014);

- Universidade da Bahia - criada em 1946 pelo Decreto-lei no 9.155, de 08 de abril de 1946, consoante Boaventura (2009), tinha como fito integrar as faculdades isoladas de Medicina, Odontologia, Farmácia, Belas Artes, Direito, Filosofia e Economia em consonância com as políticas federais.

A regulamentação, nesse primeiro momento, conforme Sampaio, Balbachesky e Peñaloza (1998, p. 5), "foi pendular", pois, explicam:

ora parecia sinalizar para a organização de universidades regionais federais, de comum acordo com os governos estaduais, fundações privadas e Governo Federal (Decreto número 19.851, de 1931), ora disciplinava, conforme verifica-se na Constituição de 34 , que os sistemas de ensino seriam de competência dos estados da Federação.

Com efeito, como observa Oliven (2002), no Estatuto - Decreto no 19.851/1931 -, as universidades, conforme o art. 6ㅇ, poderiam "ser criadas e mantidas pela União, pelos Estados ou, sob a forma de fundações ou de associações, por particulares, constituindo universidades federais estaduais e livres" (BRASIL, 1931).

Já a Constituição de 1937 suprimiu esses dispositivos, ensejando novas regulamentações que estabeleciam uma instituição padrão, mantida pela União - Universidade do Brasil, recémcriada (em 5 de julho de 1937), e transferia as demais para os estados, mediante entendimentos e condições (SAMPAIO; BALBACHESKY; PEÑALOZA, 1998).

O segundo período de desenvolvimento das universidades mantidas pelos governos estaduais teve início nos anos de 1940 e perdurou até o início da década de 60. Foi marcado por um duplo movimento: o surgimento de novas escolas e a federalização de outras, isto é, a transformação de universidades estaduais em federais. 
É desse período a Universidade Estadual do Rio de Janeiro (1950), criada pela Lei Municipal no 547, de 4 de dezembro de 1950, a partir da junção de quatro faculdades particulares, criadas na década de 30, que passavam por dificuldades financeiras (MANCEBO, 1995).

A federalização alcançou algumas das criadas no período anterior - Universidade do Paraná, Universidade da Bahia, Universidade do Recife, que já eram parcialmente mantidas pelo governo federal, além da Universidade do Rio Grande do Sul - e outras criadas posteriormente, a exemplo da Universidade da Paraíba (criada em 1955), da Universidade do Rio Grande do Norte (criada em 1958) e da Universidade de Juiz de Fora (criada em 1960) (SAMPAIO; BALBACHESKY; PEÑALOZA, 1998).

A passagem de universidade estadual para federal, segundo Sampaio, Balbachesky e Peñaloza (1998), decorreu de vários fatores: pressão dos movimentos estudantis pela ampliação do número de vagas na educação superior, apoio dos professores e funcionários que pleiteavam o enquadramento no regime dos servidores federais, bem como os parcos recursos disponibilizados pelos governos estaduais a essas instituições.

Mas o setor não experimentou apenas perdas. Na década de 1970, já após a Reforma Universitária de 1968 (Lei no 5.540/68), surgiram mais 6: Universidade Estadual de Londrina (1971), Universidade Estadual de Ponta Grossa (1973), Universidade Estadual de Campinas (1976), Universidade Estadual Paulista (1976), Universidade Estadual de Maringá (1976) e Universidade Estadual do Ceará (1977). O fato é que o setor chegou ao final do período com um total de 09 instituições (SAMPAIO; BALBACHESKY; PEÑALOZA, 1998).

O terceiro período, que tem início nos anos de 1980, é tema do próximo item.

\section{TEMPOS DE EXPANSÃO: PARTICIPAÇÃO DO SEGMENTO DAS UNIVERSIDADES ESTADUAIS NO ENSINO SUPERIOR BRASILEIRO ENTRE 1980 E 1996}

O período iniciado nos anos de 1980, diferentemente do anterior, foi marcado pela expansão. Às nove existentes em 1980 somaram-se, até 1996, ano de aprovação da Lei de Diretrizes e Bases da Educação Nacional (Lei no 9394/1996), mais 18 instituições (INEP, 2000); um crescimento de $200 \%$, menor apenas do que o verificado no setor privado, que teve uma variação de $220 \%$ (INEP, 2000), como se evidencia na tabela abaixo:

Tabela 1: Número de universidades por dependência administrativa e percentual de aumento entre 1980 e 1996.

\begin{tabular}{|c|c|c|c|c|c|}
\hline \multirow{2}{*}{$\begin{array}{c}\text { Dependência } \\
\text { administrativa }\end{array}$} & \multicolumn{2}{|c|}{1980} & \multicolumn{2}{|c|}{1996} & \multirow{2}{*}{$\begin{array}{c}\text { Cresc. (\%) } \\
1980-1996 \\
\end{array}$} \\
\hline & Abs & $\%$ & Abs & $\%$ & \\
\hline Federal & 34 & 52 & 39 & 29 & 15 \\
\hline Estadual & 9 & 14 & 27 & 20 & 200 \\
\hline Municipal & 2 & 3 & 6 & 4 & 200 \\
\hline Privada & 20 & 31 & 64 & 47 & 220 \\
\hline Total & 65 & 100 & 136 & 100 & 109 \\
\hline
\end{tabular}

Fonte: Elaboração própria a partir de dados dos Censos da Educação Superior de 1980 e de 1996 (INEP, 1980; 1996). 
Isso, como evidenciado nos gráficos abaixo, alterou a participação das estaduais no ensino superior, passando de $14 \%$ para $20 \%$ do total, enquanto as federais reduziram de $52 \%$ para $29 \%$.

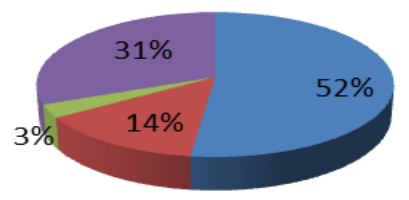

a)

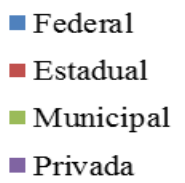

- Privada

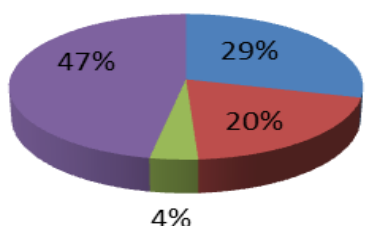

b)
Federal

Estadual

Municipal

- Privada

Gráfico 1. Percentual de universidades por dependência administrativa - a) em 1980; b) em 1996.

Essa ampliação também ocorreu no número de vagas oferecidas, ainda que, como se percebe na tabela abaixo, não tenha garantido que essas instituições mantivessem a participação que tinham nos anos de 1980 . Apesar do número de vagas nas UEs ter aumentado $122 \%$, passando de 22.731, em 1980, para 50.483, em 1996, identifica-se uma redução no percentual de participação em 7\%, em decorrência da expansão do segmento privado em 44\%.

Tabela 2: Número de vagas nas universidades por dependência administrativa e percentual de aumento entre 1980 e 1996.

\begin{tabular}{|c|c|c|c|c|c|}
\hline \multirow{2}{*}{$\begin{array}{l}\text { Dependência } \\
\text { administrativa }\end{array}$} & \multicolumn{2}{|c|}{1980} & \multicolumn{2}{|c|}{1996} & \multirow{2}{*}{$\begin{array}{c}\text { Cresc. (\%) } \\
1980-1996 \\
\end{array}$} \\
\hline & Abs & $\%$ & Abs & $\%$ & \\
\hline Federal & 62.891 & 40 & 80.693 & 22 & 28 \\
\hline Estadual & 22.731 & 14 & 50.483 & 13 & 122 \\
\hline Municipal & 4.344 & 3 & 13.375 & 4 & 208 \\
\hline Privada & 66.954 & 43 & 229.014 & 62 & 242 \\
\hline Total & 156.920 & 100 & 373.565 & 100 & 138 \\
\hline
\end{tabular}

Fonte: Elaboração própria a partir de dados dos Censos da Educação Superior de 1980 e de 1996 (INEP, 1980; 1996).

O aumento não foi capaz de contrabalançar o crescimento das universidades privadas. Como se verifica nos gráficos abaixo, este setor, que oferecia $43 \%$, passou para $62 \%$, aumentando sua participação em $44 \%$ enquanto todas as federais reduziram a participação em $45 \%$, acompanhando as estaduais. A exceção, entre as instituições públicas, coube às universidades municipais que aumentaram a participação em $33 \%$.

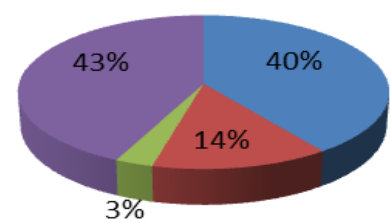

a)

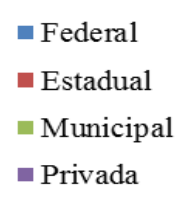

Privada

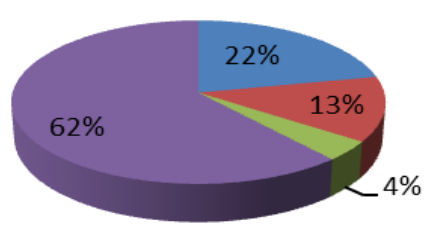

Federal

Estadual

Municipal

- Privada

b)

Gráfico 2: Percentual de vagas oferecidas nas universidades brasileiras por dependência administrativa - a) em 1980 ; b) em 1996. 
$\mathrm{O}$ aumento das vagas foi acompanhado do acréscimo no número de ingressantes. Esse número, que era de 21.341 , passou para 46.294 , um acréscimo de $117 \%$, enquanto o crescimento das federais foi de $25 \%$, das municipais, de $192 \%$, e das privadas, de $198 \%$.

Tabela 3: Número de ingressantes nas universidades por dependência administrativa e percentual de aumento entre 1980 e 1996.

\begin{tabular}{|c|c|c|c|c|c|}
\hline \multirow{2}{*}{$\begin{array}{c}\text { Dependência } \\
\text { administrativa }\end{array}$} & \multicolumn{2}{|c|}{1980} & \multicolumn{2}{|c|}{1996} & \multirow{2}{*}{$\begin{array}{c}\text { Cresc. (\%) } \\
1980-1996 \\
\end{array}$} \\
\hline & Abs & $\%$ & Abs & $\%$ & \\
\hline Federal & 59.633 & 41 & 74.761 & 24 & 25 \\
\hline Estadual & 21.341 & 14 & 46.294 & 15 & 117 \\
\hline Municipal & 4.234 & 3 & 12.333 & 4 & 192 \\
\hline Privada & 60.784 & 42 & 181.217 & 57 & 198 \\
\hline Total & 145.992 & 100 & 314.605 & 100 & 134 \\
\hline
\end{tabular}

Fonte: Elaboração própria a partir de dados dos Censos da Educação Superior de 1980 e de 1996 (INEP, 1980; 1996).

Isso fez com que a fatia das estaduais, no total de ingressantes, como demonstram os gráficos abaixo, passasse de 14 para $15 \%$, um aumento de $7 \%$.

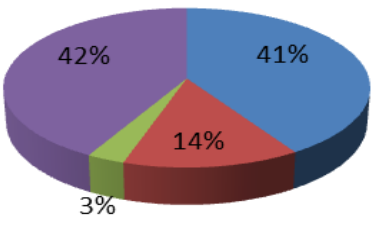

a)

$$
\begin{aligned}
& \text { Federal } \\
& \text { Estadual } \\
& \text { Municipal } \\
& \text { Privada }
\end{aligned}
$$
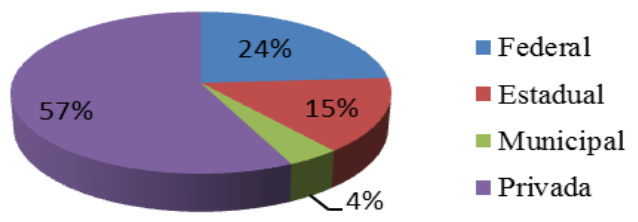

- Privada

Gráfico 3: Percentual de ingressantes nas universidades brasileiras por dependência administrativa - a) em 1980 ; b) em 1996.

Esse acréscimo, entretanto, é o menor entre as instituições que cresceram no período. As municipais aumentaram 33\% e as privadas, 36\%. As instituições federais reduziram sua participação em $41 \%$.

O aumento no número de ingressantes foi acompanhado pelo de matriculados. O número, que era de 81.723 , passou para 204.819 , um acréscimo de $151 \%$ no período, suplantando, como se constata na tabela abaixo, o das federais que cresceu apenas $22 \%$, mas sendo menor do que 0

\begin{tabular}{|c|c|c|c|c|c|}
\hline \multirow{2}{*}{$\begin{array}{c}\text { Dependência } \\
\text { administrativa }\end{array}$} & \multicolumn{2}{|c|}{1980} & \multicolumn{2}{|c|}{1996} & \multirow{2}{*}{$\begin{array}{c}\text { Cresc. (\%) } \\
1980-1996 \\
\end{array}$} \\
\hline & Abs & $\%$ & Abs & $\%$ & \\
\hline Federal & 305.099 & 47 & 373.880 & 31 & 22 \\
\hline Estadual & 81.723 & 12 & 204.819 & 17 & 151 \\
\hline Municipal & 17.019 & 3 & 47.432 & 4 & 179 \\
\hline Privada & 248.359 & 38 & 583.269 & 48 & 135 \\
\hline Total & 652.200 & 100 & 1.209 .400 & 100 & 296 \\
\hline
\end{tabular}
das privadas e das municipais.

Tabela 4: Número de matrículas nas universidades por dependência administrativa e percentual de aumento entre 1980 e 1996.

Fonte: Elaboração própria a partir de dados dos Censos da Educação Superior de 1980 e de 1996 (INEP, 1980; 1996). 
Esse aumento, como se evidencia nos gráficos abaixo, fez com que a participação das estaduais, que era de $12 \%$, passasse a ser $17 \%$, isto é, $42 \%$ maior do que era em 1980.

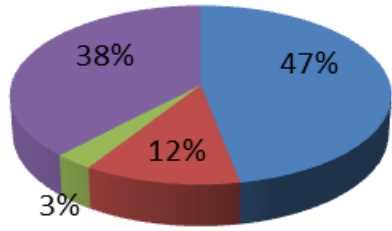

a)

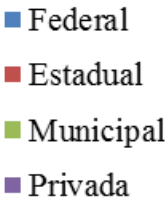

- Privada

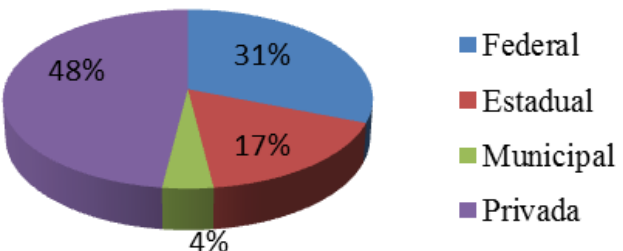

b)

Gráfico 4: Percentual de matrículas nas universidades brasileiras por dependência administrativa em 1980 e 1996 a) em 1980 ; b) em 1996.

Foi o maior crescimento do período, pois as privadas, que saíram de $38 \%$ dos matriculados para $48 \%$, elevaram sua participação em $26 \%$ e as municipais, em $33 \%$. As federais reduziram também nesse aspecto; passaram de $47 \%$ do total de matriculados para $31 \%$, o que significa que perderam $34 \%$ do total de ingressantes no período.

A expansão das matrículas repercutiu positivamente no percentual de concluintes das UEs. O número foi elevado em $148 \%$, passando de 12.197 para 30.308 , o segundo maior do setor, perdendo apenas para as universidades municipais que aumentaram $179 \%$.

Tabela 5: Número de concluintes nas universidades por dependência administrativa e percentual de aumento entre 1980 e 1996.

\begin{tabular}{|c|c|c|c|c|c|}
\hline \multirow{2}{*}{$\begin{array}{l}\text { Dependência } \\
\text { administrativa }\end{array}$} & \multicolumn{2}{|c|}{1980} & \multicolumn{2}{|c|}{1996} & \multirow{2}{*}{$\begin{array}{c}\text { Cresc. (\%) } \\
1980-1996 \\
\end{array}$} \\
\hline & Abs & $\%$ & Abs & $\%$ & \\
\hline Federal & 42.367 & 46 & 47.593 & 30 & 12 \\
\hline Estadual & 12.197 & 13 & 30.308 & 19 & 148 \\
\hline Municipal & 2.603 & 3 & 7.276 & 5 & 179 \\
\hline Privada & 34.303 & 38 & 74.001 & 46 & 116 \\
\hline Total & 91.470 & 100 & 159.178 & 100 & 115 \\
\hline
\end{tabular}

Fonte: Elaboração própria a partir de dados dos Censos da Educação Superior de 1980 e de 1996 (INEP, 1980; 1996).

Esse aumento fez com que a participação das estaduais nas conclusões dos cursos, que era de $13 \%$, passasse para $19 \%$, uma elevação de $46 \%$ no percentual de concluintes do setor, só perdendo para as municipais que ampliaram sua fatia em $67 \%$.

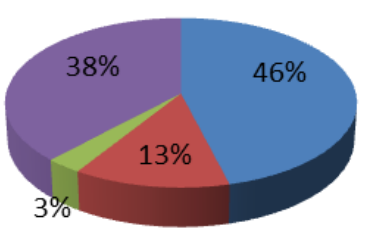

a)

\section{- Federal \\ - Estadual \\ Municipal \\ - Privada}

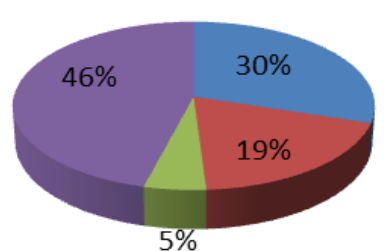

b)
- Federal

Estadual

- Municipal

- Privada

Gráfico 5: Percentual de concluintes nas universidades brasileiras por dependência administrativa - a) em 1980; b) em 1996. 
Verifica-se, então, que, até 1996, o ensino superior mantido pelos estados era o terceiro em número de instituições, vagas, ingressantes, matrículas e concluintes. Sua fatia, até então, excetuando-se em relação ao número de vagas que sofreu redução de $7 \%$ no período estudado, só ampliava, contribuindo com quase um quinto do número de universidades e de concluintes, mais de um sexto do número de ingressantes, pouco mais de um sexto do número de matrículas e pouco mais de um sétimo do número de vagas.

A Lei de Diretrizes e Bases da Educação Nacional, aprovada em 1996, introduziu mudanças no setor, em particular no que se refere à flexibilização do modelo institucional, abandonando o modelo único de universidade, vigente desde o Estatuto de 1931. Consoante Castro (2008, p. 43), "as universidades passam a conviver com diferentes instituições com funções distintas universidades de ensino e pesquisa, universidades de ensino e instituições de ensino técnicoprofissional - e também com graus diversos de autonomia". Nesse novo contexto, como ficou a participação das universidades estaduais no ensino superior? Elas inauguraram um novo momento em suas trajetórias? É o que se expõe a seguir.

\section{TEMPOS DE REDUÇÃO: PARTICIPAÇÃO DO SEGMENTO DAS UNIVERSIDADES ESTADUAIS NO ENSINO SUPERIOR BRASILEIRO ENTRE 1997 E 2013}

As universidades estaduais, após a Constituição Federal de 1988 e os regulamentos da Lei de Diretrizes e Bases da Educação Nacional, passaram a submeter-se "aos respectivos sistemas de ensino e à legislação educacional estadual, suplementar, nos termos do art. 24 da Constituição Federal" (RANIERI, 2005, p. 11). Disso, como analisa a autora, resulta "uma importante consequência de natureza constitucional": ficam às margens das ingerências "do governo federal em suas atividades acadêmicas" (RANIERI, 2005, p. 11) ao tempo em que se abrem as possibilidades de efetivo exercício da autonomia prevista no art. 207 da Constituição, com os repasses, pelos respectivos governos estaduais, de percentuais da receita decorrentes da arrecadação de impostos. A partir de então, esse segmento cresceu $27 \%$, menos da metade do verificado no segmento das federais, porém mais do que o setor privado.

Tabela 6: Número de universidades por dependência administrativa e percentual de aumento entre 1997 e 2013.

\begin{tabular}{|c|c|c|c|c|c|}
\hline \multirow{2}{*}{$\begin{array}{l}\text { Dependência } \\
\text { administrativa }\end{array}$} & \multicolumn{2}{|c|}{1997} & \multicolumn{2}{|c|}{2013} & \multirow{2}{*}{$\begin{array}{c}\text { Cresc. (\%) } \\
1997-2013\end{array}$} \\
\hline & Abs & $\%$ & Abs & $\%$ & \\
\hline Federal & 39 & 26 & 62 & 32 & 59 \\
\hline Estadual & 30 & 20 & 38 & 19 & 27 \\
\hline Municipal & 8 & 5 & 11 & 6 & 22 \\
\hline Privada & 73 & 49 & 84 & 43 & 15 \\
\hline Total & 150 & 100 & 195 & 100 & 30 \\
\hline
\end{tabular}

Fonte: Elaboração própria a partir de dados dos Censos da Educação Superior de 1997 e de 2013 (INEP, 1997; 2013).

A participação, que era de $20 \%$, ficou em $19 \%$, praticamente a mesma, como se observa nos gráficos abaixo: 


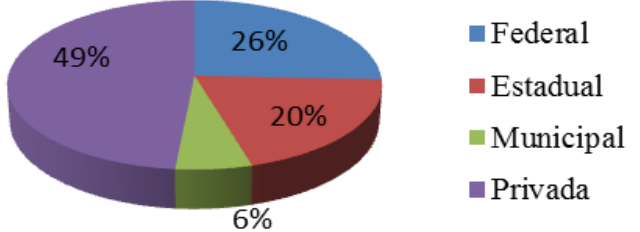

a)

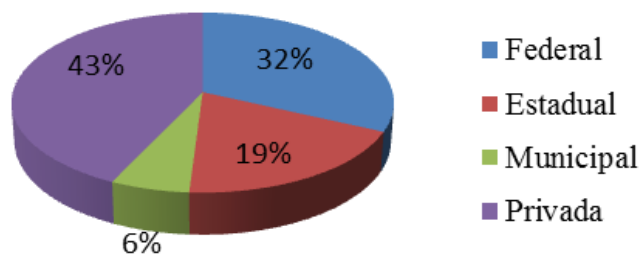

b)

Gráfico 6: Percentual de universidades por dependência administrativa em 1997 e 2013 - a) em1997; b) em 2013.

Essa estagnação refletiu-se no número de vagas. Foi o menor crescimento entre todos os setores públicos, incluindo o municipal, e em relação ao privado que cresceu mais de 600 pontos percentuais, o que fez reduzir a participação das estaduais de $12 \%$ para $5 \%$.

Tabela 7: Número de vagas nas universidades por dependência administrativa e percentual de aumento entre 1997 e 2013.

\begin{tabular}{c|c|c|c|c|c}
\hline \multirow{2}{*}{$\begin{array}{c}\text { Dependência } \\
\text { administrativa }\end{array}$} & \multicolumn{2}{|c|}{1997} & \multicolumn{2}{|c|}{2013} & \multirow{2}{*}{$\begin{array}{c}\text { Cresc. (\%) } \\
\text { Abs }\end{array}$} \\
\cline { 2 - 6 } & Abs & Abs & 2013 \\
\hline Federal & 85.178 & 19 & 271.207 & 10 & 218 \\
Estadual & 55.743 & 12 & 134.939 & 5 & 142 \\
Municipal & 20.396 & 5 & 52.222 & 2 & 156 \\
Privada & 282.093 & 64 & 2.217 .855 & 83 & 686 \\
Total & 443.410 & 100 & 2.676 .223 & 100 & 503 \\
\hline
\end{tabular}

Fonte: Elaboração própria a partir de dados dos Censos da Educação Superior de 1997 e de 2013 (INEP, 1997; 2013).

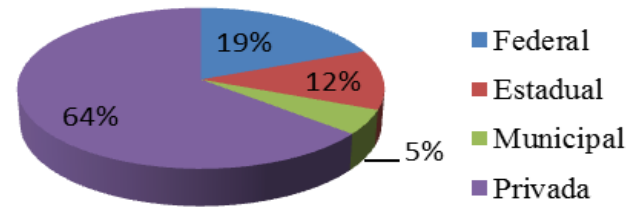

a)

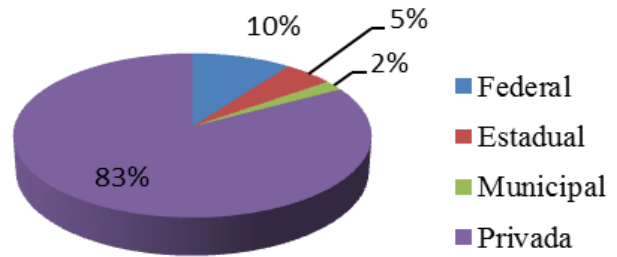

b)

Gráfico 7: Percentual de vagas oferecidas nas universidades brasileiras por dependência administrativa - a) em 1997; b) em 2013.

A redução do setor público, na oferta de vagas do ensino superior, atingiu todos os segmentos, contudo, enquanto no federal foi de $47 \%$ e, no municipal, $56 \%$, no estadual, a redução foi de $60 \%$. Essa redução, na oferta de vagas pelas UEs, repercutiu no número de ingressantes. 0 número passou de 52.878 para 115.714 , significando um crescimento de $119 \%$ que só não foi menor do que o das universidades municipais que ampliaram o número de ingressantes em $116 \%$. 
Tabela 8: Número de ingressantes nas universidades por dependência administrativa e percentual de aumento entre 1997 e 2013.

\begin{tabular}{|c|c|c|c|c|c|}
\hline \multirow{2}{*}{$\begin{array}{l}\text { Dependência } \\
\text { administrativa }\end{array}$} & \multicolumn{2}{|c|}{1997} & \multicolumn{2}{|c|}{2013} & \multirow{2}{*}{$\begin{array}{c}\text { Cresc. (\%) } \\
1997-2013 \\
\end{array}$} \\
\hline & Abs & $\%$ & Abs & $\%$ & \\
\hline Federal & 82.920 & 22 & 279.118 & 20 & 237 \\
\hline Estadual & 52.878 & 14 & 115.714 & 8 & 119 \\
\hline Municipal & 18.360 & 5 & 39.693 & 3 & 116 \\
\hline Privada & 221.980 & 59 & 954.098 & 69 & 330 \\
\hline Total & 376.138 & 100 & 1.388 .623 & 100 & 270 \\
\hline
\end{tabular}

Fonte: Elaboração própria a partir de dados dos Censos da Educação Superior de 1997 e de 2013 (INEP, 1997; 2013).

Isso fez com que o percentual de contribuição das estaduais, no total de ingressantes, como demonstram os gráficos abaixo, passasse de 14 para $8 \%$, um decréscimo de $43 \%$.

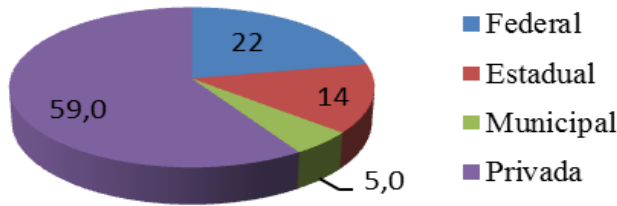

a)

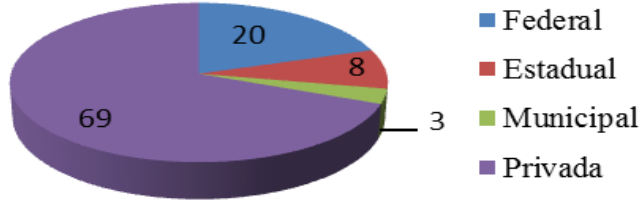

b)

Gráfico 8: Percentual de ingressantes nas universidades brasileiras por dependência administrativa - a) em1997; b) em 2013.

Essa redução foi a maior verificada no segmento público, pois, nas federais, a redução foi de $9 \%$ e, nas municipais, de $40 \%$. Já o segmento privado, diferentemente do público, apresentou um acréscimo de $17 \%$ no número de ingressantes, sendo responsável pelo maior número de entrantes nas universidades brasileiras no lapso de tempo investigado, conforme gráficos 9 e 10. $O$ decréscimo de ingressantes das UEs repercutiu negativamente no percentual de matriculados.

Tabela 9: Número de matrículas nas universidades por dependência administrativa e percentual de aumento entre 1997 e 2013.

\begin{tabular}{|c|c|c|c|c|c|}
\hline \multirow{2}{*}{$\begin{array}{l}\text { Dependência } \\
\text { administrativa }\end{array}$} & \multicolumn{2}{|c|}{1997} & \multicolumn{2}{|c|}{2013} & \multirow{2}{*}{$\begin{array}{c}\text { Cresc. (\%) } \\
1997-2013 \\
\end{array}$} \\
\hline & Abs & $\%$ & Abs & $\%$ & \\
\hline Federal & 380.980 & 29 & 1.015 .868 & 26 & 117 \\
\hline Estadual & 226.149 & 17 & 527.390 & 13 & 133 \\
\hline Municipal & 59.292 & 4 & 112.035 & 3 & 89 \\
\hline Privada & 660.038 & 50 & 2.243 .587 & 58 & 340 \\
\hline Total & 1.326 .459 & 100 & 3.898 .880 & 100 & 194 \\
\hline
\end{tabular}

Fonte: Elaboração própria a partir de dados dos Censos da Educação Superior de 1997 e de 2013 (INEP, 1997; 2013).

O percentual, que era de $17 \%$, passou para $13 \%$, reduzindo a participação em $23 \%$, conforme gráficos abaixo. 


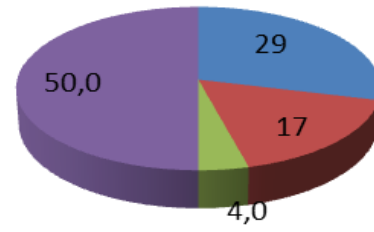

a)

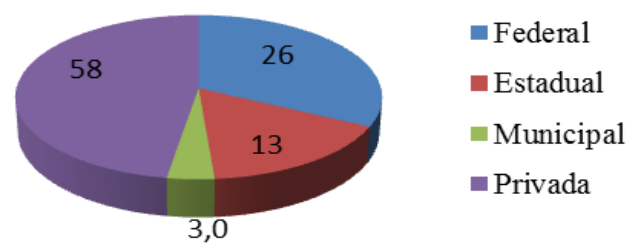

b)

Gráfico 9: Percentual de matrículas nas universidades brasileiras por dependência administrativa - a) em 1997; b) em 2013.

As demais instituições públicas também se retraíram nesse aspecto; nas federais, o percentual passou de $29 \%$ do total de matriculados para $26 \%$, o que significa que elas perderam $10 \%$ do total de ingressantes no período investigado; nas municipais, a redução foi de $25 \%$.

No setor privado, acompanhando a tendência de crescimento das variáveis analisadas anteriormente, também se identifica um aumento do percentual de matrículas, passando de $50 \%$, em 1997 , para $58 \%$, em 2013 , o que corresponde ao crescimento de $16 \%$ nesse período.

A diminuição das matrículas efetuadas pelas UEs ensejou o decréscimo dos discentes concluintes. O número reduziu em $26 \%$, o segundo maior percentual de decréscimo do segmento público, tendo em vista que, nas federais, a diminuição foi de $33 \%$ e, nas municipais, de $20 \%$.

Tabela 10: Número de concluintes nas universidades por dependência administrativa e percentual de aumento entre 1997 e 2013.

\begin{tabular}{|c|c|c|c|c|c|}
\hline \multirow{2}{*}{$\begin{array}{c}\text { Dependência } \\
\text { administrativa }\end{array}$} & \multicolumn{2}{|c|}{1997} & \multicolumn{2}{|c|}{2013} & \multirow{2}{*}{$\begin{array}{l}\text { Cresc. (\%) } \\
1997-2013\end{array}$} \\
\hline & Abs & $\%$ & Abs & $\%$ & \\
\hline Federal & 47.593 & 30 & 105.693 & 20 & 122 \\
\hline Estadual & 30.308 & 19 & 73.200 & 14 & 141 \\
\hline Municipal & 7.276 & 5 & 18.038 & 4 & 148 \\
\hline Privada & 74.001 & 46 & 324.754 & 62 & 339 \\
\hline Total & 159.178 & 100 & 521.685 & 100 & 228 \\
\hline
\end{tabular}

Fonte: Elaboração própria a partir de dados dos Censos da Educação Superior de 1997 e de 2013 (INEP, 1997; 2013).

Essa redução fez com que a participação das UEs, no total de concluintes, diminuísse de $19 \%$ para $14 \%$, embora essas instituições de ensino superior tenham apresentado crescimento de $141 \%$ nesse período, pois, em 1997, elas foram responsáveis por 30.308 e, no ano de 2013, por 73.200 estudantes concluintes.

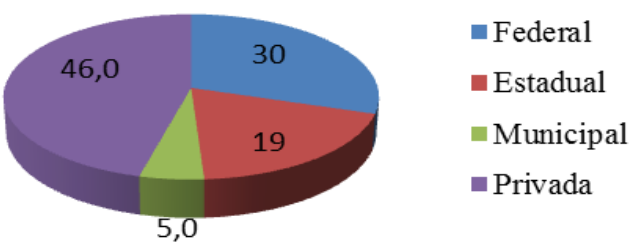

a)

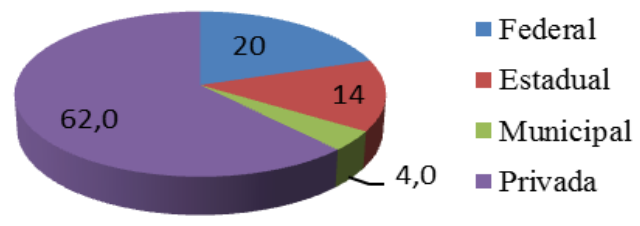

b)

Gráfico 10. Percentual de concluintes nas universidades brasileiras por dependência administrativa - a) em 1997; b) em 2013. 
Já nas universidades privadas, computa-se um acréscimo de $35 \%$, tendo em vista que, em 1997, elas foram responsáveis por $46 \%$ do total geral das universidades, passando, em 2013, para $62 \%$. Assim, essas instituições tornaram-se responsáveis pelo maior percentual de discentes concluintes no período analisado.

Verifica-se, então, que, até 2013 , o ensino superior mantido pelos estados era o terceiro em número de instituições, vagas, ingressantes, matrículas e concluintes, conservando a mesma posição do período compreendido entre 1980 e 1996. No entanto, divergentemente, a sua fatia de contribuição reduziu-se em todas as variáveis analisadas. Elas contribuíram com quase um quinto do número de universidades, um vigésimo do número de vagas, quase um treze avos do número de ingressantes, quase um oitavo do número de matrículas e pouco mais de um sétimo do número de vagas.

\section{CONCLUSÃO}

As universidades estaduais integram o ensino superior brasileiro desde o início do século XX. Foram as primeiras instituições universitárias, sendo criadas antes mesmo do Estatuto das Universidades Brasileiras (Decreto no 19.851/31), marco regulatório que estabelecia o modelo universitário como preferencial de organização do ensino superior nacional, por iniciativa de grupos de líderes políticos, intelectuais e representantes da sociedade local.

Muitas dessas instituições foram federalizadas, o que fez com que o setor ficasse, inicialmente, até os anos de 1960, reduzido. Depois, já na década de 1980, recuperou-se com a criação de 9 unidades. Desde então, até a Lei de Diretrizes e Bases da Educação Nacional, ampliou o número de universidades, vagas, ingressantes, matrículas e concluintes, aumentando sua participação em todos os aspectos analisados, exceto no de vagas que, apesar de ter crescido $122 \%$ no período, não foi capaz de suplantar o acréscimo de $242 \%$ das universidades privadas. Ainda assim, sua contribuição, que era de $14 \%$ no total de instituições, em 1980 , passou para $20 \%$; no número de ingressantes, de 14\% para 15\%; no de matrículas, de 12 para 17\%; e, no de concluintes, de $13 \%$ para $19 \%$. No de vagas, seu pior desempenho, caiu de $14 \%$ para $13 \%$.

A redução se tornaria tendência após a LDB; a participação das estaduais, no ensino superior brasileiro, diminuiu: de $20 \%$ das universidades existentes, para $19 \%$; de $13 \%$ das vagas para 5\%; de $15 \%$ dos ingressantes para $8 \%$; de $17 \%$ das matrículas para $13 \%$; e de $19 \%$ dos concluintes para $14 \%$. Isso não significa que o setor não tenha crescido, pelo contrário, o número de universidades foi acrescido em $27 \%$, o de vagas $142 \%$, o de ingressantes $119 \%$, o de matrículas $133 \%$ e o de concluintes $141 \%$. É que esses percentuais foram inferiores ao crescimento verificado entre as federais com $59 \%$ mais instituições universitárias e, principalmente, entre as privadas que aumentaram o número de vagas em $686 \%$, o de ingressantes em $330 \%$, o de matrículas em $340 \%$ e o de concluintes em $339 \%$. Por isso, a fatia das estaduais, no ensino superior, reduziu: $5 \%$ no total de universidades, $60 \%$ no de vagas, $43 \%$ no de ingressantes, $23 \%$ no de matrículas e $26 \%$ no de concluintes.

As profundas alterações no ensino superior universitário, introduzidas pela Lei de Diretrizes e Bases da Educação Nacional, então, favoreceram o setor privado, tornando-o o maior segmento. O mesmo não aconteceu com as estaduais. Para elas, a flexibilização, a não sujeição aos regramentos do sistema federal e, principalmente, a autonomia e repasse de percentuais de 
receita pelos estados não lhes garantiram expansão. Pelo contrário, como atestam os números, fizeram-na crescer menos do que as demais, encolhendo sua participação, e isso explica por que, provavelmente, enfrentem dificuldades.

Talvez isso ocorra, resta examinar, porque esses repasses não tenham sido instituídos ou sejam insuficientes para sua manutenção, como indicam os movimentos da Associação Brasileira dos Reitores dos Centros Universitários e Universidades Estaduais e Municipais (ABRUEM, 2014) e do Congresso Nacional pela criação de um fundo federal específico, nos moldes do Fundo de Manutenção e Desenvolvimento da Educação Básica e de Valorização dos Profissionais da Educação (FUNDEB), com recursos do pagamento da dívida dos estados com a União para a educação superior estadual.

Conclui-se, então, que a participação das universidades estaduais, no ensino superior brasileiro, tem experimentado ora ampliação, ora redução, mas sempre favorece o acesso ao ensino superior de grandes camadas da população brasileira.

\section{REFERÊNCIAS BIBLIOGRÁFICAS}

1. ASSOCIAÇÃO BRASILEIRA DOS REITORES DAS UNIVERSIDADES ESTADUAIS E MUNICIPAIS. ABRUEM-2014. Financiamento das Universidades Públicas. Disponível em: <http: // www.abruem.org.br/noticias/1984>. Acesso em 27 nov. 2014.

2. BOAVENTURA, Edivaldo M. A Construção da Universidade Baiana: origens, missões e afro descendência. 1. ed. Salvador - BA: Edufba, 2009. v. 1. 272p.

3. BRASIL. Decreto 19.851, de 11 de abril de 1931. Dispõe sobre o ensino superior no Brasil obedecerá, de preferencia, ao systema universitário, podendo ainda ser ministrado em institutos isolados, e que a organização technica e administrativa das universidades é instituída no presente Decreto, regendo-se os institutos isolados pelos respectivos regulamentos, observados os dispositivos do seguinte Estatuto das Universidades Brasileiras. Rio de Janeiro. 1931. Disponível em: < http://www2.camara.leg.br/legin/fed/decret/1930-1939/decreto19851-11-abril-1931-505837-publicacaooriginal-1-pe.html> Acesso em: 23 nov. 2014.

4. BRASIL. Constituição brasileira de 10 de novembro de 1937. Brasília: Senado Federal, 1999. Disponível em: < http://www2.senado.leg.br/bdsf/bitstream/handle/id/137571/Constitui coes_Brasileiras_v4_1937.pdf?sequence=9> Acesso em: 25 nov. 2014.

5. BRASIL. Lei 9.394, de 20 de dezembro de 1996. Estabelece as diretrizes e bases da educação nacional. Brasília: 1996. Disponível em: < http://www.planalto.gov.br/ccivil_03/leis/19394. htm>. Acesso em: 25 nov. 2014.

6. CARDOSO, I. R.. A Universidade da Comunhão Paulista. São Paulo: Editora Cortez, 1982.

7. CASTRO, Fabiana Rodrigues de Almeida. Os sentimentos, percepções e práticas de docentes e discentes do Curso de Administração da Universidade Federal do Piauí, em Teresina, como reflexo da expansão do ensino superior privado. Teresina: 2008. 122fls. Dissertação (Mestrado em Políticas Públicas). Programa de Pós Graduação em Políticas Públicas, UFPI, 2008.

8. INEP. Instituto Nacional de Estudos e Pesquisas Educacionais Anísio Teixeira. Sinopse Estatística do Ensino Superior: 1980. Brasília: MEC/INEP/DEED, 1980. Disponível em: < http://portal.inep.gov.br/superior-censosuperior-sinopse>. Acesso em: 24 set. 2014. 
9. INEP. Instituto Nacional de Estudos e Pesquisas Educacionais Anísio Teixeira. Sinopse Estatística do Ensino Superior: 2000. Brasília: MEC/INEP/DEED, 2000. Disponível em: < http://portal.inep.gov.br/superior-censosuperior-sinopse>. Acesso em: 24 set. 2014.

10. Sinopse Estatística do Ensino Superior: 1996. Brasília: MEC / INEP / DEED, 1996. Disponível em < http://portal.inep.gov.br/superior-censosuperior-sinopse>. Acesso em: 24 set. 2014.

11. Sinopse Estatística do Ensino Superior: 1997. Brasília: MEC/INEP/DEED, 1997. Disponível em: < http://portal.inep.gov.br/superior-censosuperior-sinopse>. Acesso em: 24 set. 2014.

12. Sinopse Estatística do Ensino Superior: 2013. Brasília: MEC/INEP/DEED, 2013. Disponível em: < http://portal.inep.gov.br/superior-censosuperior-sinopse>. Acesso em: 24 set. 2014.

13. MANCEBO, Deise. A História da Universidade do Estado do Rio de Janeiro: da gênese aos compromissos. In: VI Seminário Nacional de História da Ciência e da Tecnologia, 1997, Rio de Janeiro. Anais do VI Seminário Nacional de História da Ciência e da Tecnologia, 1997. v. 6. p. 198-202.

14. OLIVEN, A. C. Histórico da educação superior no Brasil. In: SOARES, Maria Susana Arrosa (Coord.). (Org.). A Educação Superior no Brasil. Brasília - DF: CAPES, 2002, v. 1, p. 31-42.

15. RANIERI, N. B. S. (Org.). Autonomia Universitária na USP. São Paulo: EDUSP, 2005. v. 2. 401p .

16. SAMPAIO, H.; BALBACHESKY, E.; PEÑALOZA, V. Universidades Estaduais no Brasil: características institucionais. São Paulo: NUPES/USP, 1998.

17. UNIVERSIDADE FEDERAL DO RIO GRANDE DO SUL. UFRGS - 2014. Histórico da Universidade Federal do Rio Grande do Sul. Disponível em: < http:// www.ufrgs.br / a-ufrgs/histórico >. Acesso em: 20 de nov.2014. 